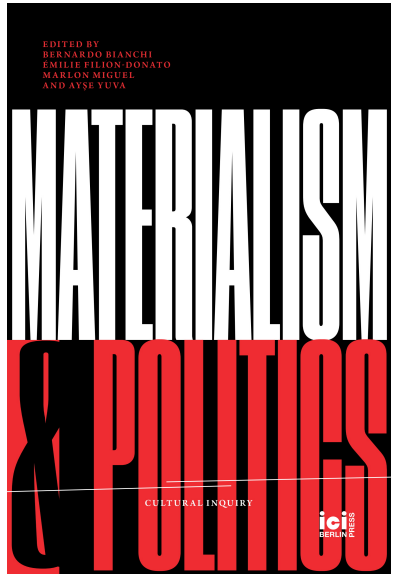

Materialism and Politics, ed. by Bernardo $\mathrm{Bi}$ anchi, Emilie Filion-Donato, Marlon Miguel, and Ayşe Yuva, Cultural Inquiry, 20 (Berlin: ICI Berlin Press, 2021), pp. 233-52

\section{ÉMILIE FILION-DONATO}

\section{Psychodynamism of Individuation and New Materialism \\ Possible Encounters}

CITE AS:

Émilie Filion-Donato, 'Psychodynamism of Individuation and New Materialism: Possible Encounters', in Materialism and Politics, ed. by Bernardo Bianchi, Emilie Filion-Donato, Marlon Miguel, and Ayşe Yuva, Cultural Inquiry, 20 (Berlin: ICI Berlin Press, 2021), pp. 233-52 <https://doi.org/10.37050/ci-20_13>

\section{RIGHTS STATEMENT:}

(C) by the author(s)

Except for images or otherwise noted, this publication is licensed under a Creative Commons Attribution-ShareAlike 4.0 International License.

ABSTRACT: In this chapter, I explore the possible benefits of combining an analysis of the psychodynamism of individuation with New Materialism. I contend that concepts such as dynamic objectivity and autonomy can help us to understand the specificity of human agential cuts proposed by New Materialism. This, in turn, opens up possible answers to ethical difficulties left entangled by New Materialism's posthumanist approach to ethico-onto-epistem-ology.

KEYWORDS: new materialism; psychodynamism of individuation; epistemology; feminism; ontology; ethics; situation (philosophy); FoxKeller, Evelyn; Barad, Karen 


\section{Psychodynamism of Individuation and New Materialism \\ Possible Encounters}

ÉMILIE FILION-DONATO

Organizing life according to differences, be they sexual $(\text { male } / \text { female })^{1}$ or otherwise, ${ }^{2}$ is a social praxis. Indeed, feminists have long argued that though it may be possible to group humans into two groups based on differences which we call sexual, the meaning we ascribe to these differences and the impact we allow them to have is unequivocally social. In other words, what we make of these differences and the psychological and material consequences they

1 It has been suggested that I may mean 'gendered' here. Though I personally believe, with Anne Fausto-Sterling (Sexing the Body: Gender Politics and the Construction of Sexuality, rev. edn (New York: Basic Books, 2000)), Thomas Laqueur (Making Sex: Body and Gender from the Greeks to Freud (Cambridge, MA: Harvard University Press, 2003)), and others, that sex is a scientific construct, using 'gender' here would be misleading because what I am referring to are the perceived physical differences not the social roles extrapolated from the same. Whether these differences are really relevant for deducing any personality or group traits or whether they have been exacerbated (or even constructed) by the superimposed (cultural) bicategorization are a different set of questions (to which I answer: no and yes.)

2 Though other differences, such as 'racial' differences, those pertaining to neuronal or bodily ability, sexual orientation, or those of socio-economic circumstances, have been of equal importance in this social organization of difference, I focus on gender difference here because the epistemologists I study base their theoretical framework on the construction of this specific difference. 
result in arise from socio-cultural interactions, alliances - whether explicit or not - and more or less fixed arrangements. Second, feminists have argued that such practices enable the emergence of two different cultures (men/women) (gender), ${ }^{3}$ which, through some combination of feedback loops and confirmation biases, reinforce the significance and importance given to the alleged sexual differences. That is, by rewarding members of an in-group for a certain set of behaviours and punishing or discouraging other behaviours, as well as ascribing the converse undesirable behaviours to the out-group, each culture participates in exacerbating and amplifying intergroup differences.

This dynamic reinforcement of differences has important consequences for epistemology. Indeed, many epistemologists argue that knowledge production is a specifically human endeavour which is inextricable from its historical, local, and social context. As a result, according to this viewpoint, knowledge is permeable to cultural or group biases. Feminist epistemologists combined these two insights - the existence of gendered cultures and the permeability of knowledge to culture - and began to ask in the 1970s whether, and if so, how, male cultural (androcentric) biases have impacted the production of scientific knowledge. In other words, if we accept that the way gender

3 When I use men or women, I mean the cultural extrapolations from the bodily characteristics (when I mean those, I use male/female). Nicole Claude Mathieu has suggested that there are three paradigms to think of the relationship between sex and gender. In the first, social sex (gender) is undissociated from biological sex (sex). Under this paradigm, all that we associate with the feminine (gender) is a direct and faithful translation of the (female) biological condition and can only be explained by it (Nicole-Claude Mathieu, L'Anatomie politique: catégorisations et idéologies du sexe (Paris: Côté-femmes: 1991)). The second paradigm proposes that the social sex symbolizes the biological sex. That is to say, that the first (gender) refers to the second (sex) and is related to it in some way, without being absolutely determined by it. In this paradigm, if biology is not the only determinant of (gendered) behaviour, it is because there is, according to these theories, a number of codes and norms that are learned by individuals, voluntarily or not. The third conceptualization proposes that the obstinacy to confine the heterogeneity of the biological condition to two categories actually comes from the social system which frames or orients the reading of biological data. This conceptualization proposes that the network of norms and codes that governs bodies and pushes them to conform to one of the two groups has the purpose of simplifying social interactions. Because of this simplification, the social model of bicategorization is preferred to more complex models, such as those in which heterogeneity of sex would be accepted. As a result, the data invalidating the dimorphic model are either ignored or reinterpreted in favour of the coherence of the system. 
and gender roles are expressed at any given time is a social praxis, and we also accept that knowledge emerges out of a specific cultural context, then the praxis of gender has to be taken into account as part of the general social context from which this knowledge emerges.

This chapter relies upon my own typology of the strategies put forward by U.S. feminists in response to the problem of androcentrism in the production of knowledge. Briefly put, this typology groups the various feminist strategies into three categories: 'changing the subject', 'multiplying the subject', and 'decentring the subject'.'

This chapter has two goals. The first is to challenge the category of strategies Helen Longino, in 'Subjects, Power, and Knowledge', ascribes to biologist and epistemologist Evelyn Fox Keller and her strategy: psychodynamism of individuation. ${ }^{5}$ The second goal of this chapter is to underline how psychodynamism of individuation and New Materialism can benefit one another, emphasizing the interrelations between them and discussing their relationship to Spinozist materialism.

In her 1993 essay, Longino places Keller in the category she calls — and which I use with some adjustments - 'changing the subject'. According to Longino, this category contains two different strategies: Keller's psychodynamism of individuation and standpoint theory. ${ }^{6}$ Longino groups these two strategies together because she believes that they have similar consequences for rethinking how science should be done. That is, in her opinion they both attempt to change who is doing science (what we could call the epistemic subject). Contra Longino,

4 The first two categories are inspired by Helen E. Longino, 'Subjects, Power, and Knowledge: Description and Prescription in Feminist Philosophies of Science', in Feminist Epistemologies, ed. and intro. by Linda Alcoff and Elizabeth Potter (New York: Routledge, 1993), pp. 101-20. The last category is my own.

5 Ibid.

6 Very briefly, 'standpoint theory', the genealogy of which can be traced back to Marxism and Black feminism, argues that the subject of knowledge's position (be it their gender, 'race', socio-economic background, sexual orientation, mental and physical ability, etc.) has an influence on the type and quality of knowledge produced. Hence, epistemic authority is given to certain people on specific topics. For example, it will be assumed a black woman has access to specific knowledge about the condition of black women in general, something that cannot be spontaneously known to someone who is not part of this group (see Patricia Hill Collins, 'Learning from the Outsider Within: The Sociological Significance of Black Feminist Thought', Social Problems, 33.6 (1986), pp. 14-32). This is not strictly speaking an epistemology based on identity since this position can change during one's lifetime. 
I argue that Keller's use of object-relation theory allows ontological insights and consequences that are irreducible to a change of the epistemic subject of the sort proposed by standpoint theory. Instead, I propose that Keller forgoes substantial ontology in favour of relational ontology. To help make this point, I place Keller's psychodynamism of individuation in relation with New Materialism, a strategy found in my third category (decentring the subject) where I also place Keller's psychodynamism of individuation.

This discussion sets the stage for the second goal of this chapter which is to underline how both strategies (New Materialism and psychodynamism of individuation) can benefit one another. Particularly, I endeavour to show how Keller's psychodynamism of individuation can help address some of the most devastating criticisms directed at New Materialism. These criticisms are twofold. First, some have contended that the ontology in New Materialism revives the threat of idealism (understood as anti-realism) because the subject of knowledge is also part of the apparatus and hence can impact the phenomena solely through its presence. ${ }^{7}$ Second, others have reproached the ontology of New Materialism for making collective action difficult, and even impossible, given the éclatement of the (human) subject. ${ }^{8}$ Indeed, in this multiverse of forces, ascribing responsibility can seem difficult. I shall address these criticisms at the end of this paper.

In brief, this paper aims to encourage reflection on an epistemological project that takes both psychic structures and matter seriously by achieving a cross-pollination of New Materialism and the psychodynamism of individuation. My hope is that this cohabitation can lead to more democratic epistemologies. Before going into the details of this cross-pollination, however, I will first situate myself in the materialist tradition, for it would be remiss of me not to mention the impact of Baruch Spinoza on this project. I have borrowed many ideas from Spinoza but principally his monism and immanent causality. Both

7 Andreas Malm, The Progress of This Storm: Nature and Society in a Warming World (London: Verso, 2018); Andreas Malm, 'Against Hybridism: Why We Need to Distinguish between Nature and Society, Now More than Ever', Historical Materialism, 27.2 (2019), pp. 156-87.

8 Malm, 'Against Hybridism'; Eva Bendix Petersen, “Data Found Us”: A Critique of Some New Materialist Tropes in Educational Research', Research in Education, 101.1 (2018), pp. 5-16. 
concepts, in my opinion, are remedies to the impasses of teleological thinking, which is the source of most biases or 'ideologies' in Louis Althusser's sense.

\section{MATERIALISM}

I understand being a materialist in the sense of being a dedicated monist. This monism is inspired by Spinoza's monism in that it is committed to using the same methodology when considering the causal relationships of the attribute of Thought as much as that of Extension. Indeed, in the Ethics, Spinoza writes:

I shall treat the nature and powers of the Affects, and the power of the Mind over them, by the same Method by which, in the preceding parts, I treated God and the Mind, and I shall consider human actions and appetites just as if it were a Question of lines, planes, and bodies. ${ }^{9}$

As such, this methodology means committing to monism even when it seems not to correspond to traditional notions of materialism: i.e., when thinking about social relations as well as psychological forces and states. Arguing for the contrary - that social relations or psychological states have no impact on a phenomenon - is, in my view, to take a dualist stance and claim that psychic and social formations are somehow supra material.

This monism is also, in my opinion, what connects ontoepistemological materialism, or scientific materialism, ${ }^{10}$ and historical materialism, both of which are encountered in this volume. The first is a materialism which can be traced back to Democritus and Epicurus and which we associate with a scientific kind of understanding. According to this type of materialism (and monism), matter is the only thing that exists. This school of thought is also known as

9 Spinoza, Ethics III, Praef.; CWS [The Collected Works of Spinoza, see abbreviations], I, p. 492.

10 The use of 'scientific' here may lead to some confusion as Marx has been known to use the term 'scientific socialism' or 'communism' to refer to his ideas in opposition to the 'utopian socialism' of the kind proposed by Fourier and Saint-Simon (see Raymond Aron, Le Marxisme de Marx (Paris: Editions de Fallois, 2002), p. 579.). I shall use scientific here only to refer to the contemporary sense of 'natural sciences'. 
physicalism. Hence, there is no god-like or soul-like force ${ }^{11}$ that can make matter bend the rules of its nature. The second, historical materialism, is a materialism which can be traced back to Marx and has more to do with a socio-history which encourages us to learn more about social determinations in order to enact socio-political change. In this sense, I understand Marx's methodology as monist since social relations are analysed on the same plane as natural phenomena. ${ }^{12}$ It is a more complex monism than physicalism, but a monism in its methodology nonetheless. ${ }^{13}$

This 'taking into account' of social relations and psychological states as elements that constitute a phenomenon, however, has often been reduced to radical constructivism or dismissed as such by the first kind of materialism (onto-epistemological). ${ }^{14}$ Such a dismissal seems to suggest that taking more 'data' into account when considering a phenomenon is alien to science or the scientific method when, in fact, the contrary should be true. In my opinion, this suggestion is the result of some confusion around the ideas of contingency and necessity. Indeed, to say that psychic and social formations may impact matter and vice versa is understood as suggesting that 'things', meaning matter, could have been different (say, if we hadn't interfered). That is, it is understood as saying that 'things' (or even laws of nature) are contingent because it seems that if social and psychic formations

11 Though some New Materialists use the terms 'vitality' and 'material vitalism' (e.g. Jane Bennett), they make a point of distancing themselves from older forms of vitalism (which are closer to the idea of a soul). Bennett writes 'Mine is not a vitalism in the traditional sense; I equate affect with materiality, rather than posit a separate force that can enter and animate a physical body' (Jane Bennett, Vibrant Matter: A Political Ecology of Things (Durham, NC: Duke University Press, 2010), p. xiii). So my point here is that the traditional form of vitalism is an error that leads to a dualist and teleologistic mode of thinking (though this is might not be the case with the new uses of 'vitality' and 'vitalism').

12 Marlon Miguel has correctly pointed out that not all scholars of Marx would agree with the presentation of his philosophy as monist. While it is true that the question of monism in Marx is complex, I believe his methodology is more straightforwardly monist. Žižek has argued, for example, that it is a dialectical monism (see citation below).

13 Slavoj Žižek, Absolute Recoil: Towards a New Foundation of Dialectical Materialism (London: Verso: 2014), pp. 5-15.

14 Donna J. Haraway, 'Situated Knowledges: The Science Question in Feminism and the Privilege of Partial Perspective', Feminist Studies, 14.3 (1988), pp. 575-99; Ian Hacking, The Social Construction of What? (Cambridge, MA: Harvard University Press, 1999). 
have anything to do with matter, then the latter might be changed at will. As a consequence, this supposed contingency of matter is understood as a kind of anti-realism, in the sense that it seems to suggest that some external (human or god-like) will has more bearing on the way matter behaves than any intrinsic laws of its nature. This is a misunderstanding. Spinoza, through his rejection of the very notions of Beginning and End, ${ }^{15}$ shows that social and psychic formations are no more free than gravity is. He writes in a Letter 58:

[C]onceive now, if you will, that while the stone continues to move, it thinks, and knows that as far as it can, it strives to continue moving. Of course, since the stone is conscious only of its striving, and not at all indifferent, it will believe that it is very free, and that it perseveres in motion for no other cause than because it wills to. This is that famous human freedom everyone brags of having, which consists only in this: that men are conscious of their appetite and ignorant of the causes by which they are determined. ${ }^{16}$

Indeed, Spinoza's ontology alerts us to this misconception and proposes ways out of it. ${ }^{17}$ First, his notion of a unique and immanent substance throws off the finalist-bias. Second, he shows that the Scholastic notions of necessity and contingency are errors of the same kind: the result of finite modes investing a teleological quality into Nature. ${ }^{18}$ It is this teleological investment, which Spinoza understands as imaginary, that makes us both conceive of a will (ours or God's) that

15 Louis Althusser saw this in Spinoza as well as a long tradition of materialist thinkers. He writes in 'The Underground Current of the Materialism of the Encounter', in Philosophy of the Encounter: Later Writings, 1978-87, ed. by François Matheron and Oliver Corpet, trans. by Geoffrey M. Goshgarian (London: Verso, 2006), pp. 163207: 'from Epicurus to Marx [via Spinoza], there had always subsisted - even if it was covered over (by its very discovery, by forgetfulness, and, especially, by denial and repression, when it was not condemnations that cost some their lives) - the "discovery" of a profound tradition that sought its materialist anchorage in a philosophy of the encounter (and therefore in a more or less atomistic philosophy, the atom, in its "fall", being the simplest figure of individuality). Whence this tradition's radical rejection of all philosophies of essence (Ousia, Essentia, Wesen), that is, of Reason (Logos, Ratio, Vernunft), and therefore of Origin and End' (p. 188; emphasis in the original).

16 Ep. LVIII [G. H. Schuller]; CWS II, p. 428.

17 For more on his ontology and the consequences on the notions of Freedom and Necessity, see Stefano Visentin in this volume.

18 See Ericka Itozaku's paper in this volume for a more in-depth discussion of this issue. 
shapes things into what it wants and also imagines things as contingent. However, Spinoza shows that the laws underlying the nature of finite things depend upon other finite modes that constitute and limit it.

Once we get rid of this teleological illusion, the epistemological and ethical tasks before us become, in Spinozist terms, to sit with and consider our power in its finitude, i.e., in how it is limited by other finite modes. Consequently, my argument is that what has been missing from the materialist projects (both onto-epistemological materialism and scientific materialism) is this understanding of our finitude, and consequently Spinoza's ethical project. This finitude, however, is not to be understood as a kind of fatalism, as pointed out in the introduction to this volume. Instead, understanding what has determined our lives is the very thing that sets us free from depleting affects (shame, guilt, anger, etc.), allowing us to persevere in our being more joyously, i.e., powerfully, and, in so doing, change how we relate to other finite beings and our environment. Freedom is, as Engels would later write, the appreciation of necessity. ${ }^{19}$ Hence, this change should not be conceived as a freely made decision that can direct the will here or there; instead, it is more like a fine tuning of our response to the finite beings that constitute us and which we constitute in return, and this results in a better agreement with ourselves and those around us (be they human or otherwise). This co-constitution of finite things and the fine tuning to what surrounds us is something we also find in the strategy of New Materialism, which I will now discuss.

19 Friedrich Engels, Anti-Dühring, in MECW [Marx \& Engels Collected Works, see abbreviations], $\operatorname{xxv}$ (1987), pp. 1-309 (p. 105). 


\section{FEMINIST STRATEGIES}

\section{New Materialism}

Though many scholars have written on this topic, ${ }^{20}$ I will focus here on Karen Barad's account of New Materialism. Barad's method, which she calls the Diffractive Method, is also a metaphor that was inspired by Haraway and quantum physics. It is used as a critical response to representationalist metaphors of reflection. Haraway writes about such metaphors, saying that 'both are optical phenomena, but whereas reflection evokes themes of mirroring and sameness, diffraction is marked by patterns of difference. ${ }^{21}$ She adds that 'a diffraction pattern does not map where differences appear, but rather maps where the effects of differences appear. ${ }^{22}$ This method, therefore, allegedly helps us to better attend to the relational nature of difference.

Using diffraction as a metaphor can help change the way that we perceive and interpret objects in two important ways. First, it helps shift the focus away from the intrinsic characteristics of 'objects'. That is, we can see that what is expressed and hence measured, i.e. that which emerges as the 'characteristics of the waves', actually emerges from the meetings of a 'prior' set of waves. Because any measured 'crest' does not actually exist before its meeting with the other crest, and/or the meeting with the diffracting apparatus - e.g. an island or a rock - Barad calls this meeting an intra-action in contrast to an inter-action. The

20 Rick Dolphijn and Iris van der Tuin, New Materialism: Interviews \& Cartographies (Ann Arbor, MI: Open Humanities Press, 2012); Birgit Van Puymbroeck and N. Katherine Hayles, "Enwebbed Complexities": The Posthumanities, Digital Media and New Feminist Materialism', DiGeSt: Journal of Diversity and Gender Studies, 2.1-2 (2015), pp. 21-29; Bennett, Vibrant Matter; Diana Coole and Samantha Frost, 'Introducing the New Materialisms', in New Materialisms: Ontology, Agency, and Politics, ed. by Diana Coole and Samantha Frost (Duke University Press, 2010), pp. 1-43; Rosi Braidotti, Metamorphoses: Towards a Materialist Theory of Becoming (Oxford : Blackwell, 2002); Elizabeth A. Grosz, The Nick of Time: Politics, Evolution, and the Untimely (Durham, NC: Duke University Press, 2004); Elizabeth A. Grosz, Volatile Bodies: Toward a Corporeal Feminism (Bloomington: Indiana University Press, 1994); Mariam Fraser, Sarah Kember, and Celia Lury, 'Inventive Life: Approaches to the New Vitalism', Theory, Culture \& Society, 22.1 (2005), pp. 1-14.

21 Barad, Meeting the Universe Halfway: Quantum Physics and the Entanglement of Matter and Meaning (Durham, NC: Duke University Press, 2007), p. 71.

22 Donna Haraway, 'The Promises of Monsters: A Regenerative Politics for Inappropriate/d Others', in Cultural Studies, ed. by Lawrence Grossberg, Cary Nelson, and Paula A. Treichler (New York: Routledge, 1992), pp. 295-337 (p. 300), emphasis removed. 
nuance is important because inter-action presupposes the existence of some fully formed 'actants' present 'before the meeting', whereas intraaction stresses the co-constitution of those 'actants'. This move from inter-action to intra-action therefore requires one to shift 'the primary epistemological unit' from 'things' to phenomena, i.e. from an interaction between pre-existing relata to boundary forming intra-action in phenomena. Shifting our analysis from 'things' to 'phenomena' also underlines the inseparability of 'intra-acting' 'components.' ${ }^{23}$

Second, diffraction is a helpful metaphor because it is, especially in the case of light, hard to observe without some special apparatus. Indeed, without the use of a certain set of tools, it may have always been assumed that light only behaved in a particle-like way, i.e. as matter and not as waves. Two things happen with this metaphor. First, it emphasizes humans' (in)capacity to detect, observe, or fully grasp something without a special set of tools and techniques. Second, it emphasizes the active dynamic role humans take, with or without apparatuses, in '(re)configurings of the world. ${ }^{24}$ Therefore, the metaphor is not only helpful to transition from an ontology of 'objects' towards one of 'phenomena', but it is also useful to understand how specific practices shape 'where the effects of differences appear. ${ }^{25}$ The method/metaphor thus helps us understand how our very measuring practices are neither innocent nor inconsequential.

However, this insight confronts us - perhaps ironically — with some problems reminiscent of those faced by an 'anti-realist' or even radical relativist perspective. Indeed, if everything we do, down to how we perceive, has an impact on the things we measure or want to talk about, how can we ever be sure we are getting the 'right' measurements? Further, without an agreed upon measurement, i.e. a shared account of the world, how can we understand one another, let alone, and more importantly, act collectively? Another problem, which is not an anti-realist one per se but is still relevant to the discussion at hand, is how to make sense of responsibility given this fragmented, or even

23 Karen Barad, 'Posthumanist Performativity: Toward an Understanding of How Matter Comes to Matter', Signs: Journal of Women in Culture and Society, 28.3 (2003), pp. 801-31 (p. 815).

24 Ibid., pp. 816, 818, 819, 821, 822, and 828.

25 Haraway, 'The Promises of Monsters', p. 300. 
erased, subject. I suggest that part of the answer to this can be found in Evelyn Fox Keller's use of the psychodynamism of individuation.

\section{Psychodynamism of Individuation}

Keller points out that, as is illustrated by the biblical use of 'knowing', and contrary to Bacon's infamous proposition that 'knowledge is power', knowledge needs not only be about power but can instead also have to do with connection. Keller argues that this second possibility has been largely ignored. ${ }^{26}$ Furthermore, she argues that knowledge's relationship to power has been overblown to such an extent that domination metaphors permeate scientific writing and thinking. ${ }^{27}$ She stresses that the relationship to nature is all too often expressed in terms of scientists 'attacking' or 'solving' nature, or of 'conquering' her/it - implying that something about nature will, through the attack, conquest, or discovery of a solution, disappear and make way for the scientist's vision and will.

In Keller's opinion, this conception of knowledge resembles a conception of objectivity in which the knowing subject, in order to be objective, has to be detached from her object of study. This (mis)conceptualization of objectivity is due, she argues, to a specific (mis)conception of autonomy wherein there is a 'tacit implication $[\ldots]$ that autonomy can be bought only at the price of unrelatedness. ${ }^{28}$ The shared ideal of un-relatedness in both autonomy and objectivity has persuaded her to explore the interaction between emotional and cognitive experiences and development. Not only does this shared ideal suggest that the two are related, but Keller's hypothesis is that her study could help uncover the idea that they are, in fact, co-constitutive. In order to explore this relation between objectivity and autonomy, Keller turns to the object-relation theory of German psychoanalyst Ernst Schachtel and his take on the 'psychodynamism of individuation'.

26 Evelyn Fox Keller, Reflections on Gender and Science (New Haven, CT: Yale University Press, 1995), pp. 115-16.

27 Ibid., p. 123.

28 Ibid., p. 72. 
In traditional Freudian psychoanalysis, the process of individuation, i.e. ego formation, is thought of as the more or less tragic consequence of a self-awareness, or the delineation between inner and outer stimuli, that develops as a result of unfulfilled needs. Freud writes:

An infant at the breast does not as yet distinguish his ego from the external world as the source of the sensations flowing in upon him. He gradually learns to do so, in response to various promptings. He must be very strongly impressed by the fact that some sources of excitation, which he will later recognize as his own bodily organs, can provide him with sensations at any moment, whereas other sources evade him from time to time — among them what he desires most of all, his mother's breast — and only reappear as a result of his screaming for help. ${ }^{29}$

That is, by realizing that her mother cannot and is not fulling her needs, the child understands that she is not, in fact - and this is contrary to what she may have initially thought/felt - one with her mother or the world. This is a traumatic experience for the child who then realizes that she must turn outward to satisfy unmet needs, and this towards an external world over which she has little control. This initiation into self-consciousness is condemned, for Freud, to a separation from the mother/world because it destroys the symbiotic illusion. This makes the child's relationship to the world conflictual, but also de facto oriented towards instrumentalization. Though Freud acknowledges that this feeling of connectedness with the world (or symbiosis) may subside in some adults, something he calls in this context the oceanic feeling, he claims not to recognize it in himself and proceeds to link it to some primitive pre-individuated ego. ${ }^{30}$ Because of this, the oceanic feeling speaks to, for him, some (regressive) longing to (re) unite with the world/mother.

Schachtel has a different understanding of that dynamic of individuation. For the latter, fulfilling unmet needs is one of two types of interest the child can have for the world. According to Schachtel,

29 Sigmund Freud, Civilization and its Discontents, in The Standard Edition of the Complete Psychological Works of Sigmund Freud, ed. by James Strachey, trans. by Angela Richards, 24 vols (London: Hogarth Press and the Institute of Psycho-Analysis, 1953-74), xxI (1961), pp. 57-145 (p. 67).

30 Ibid., pp. 64-65. 
the child is first and foremost turned towards the world by a curiosity and pleasure that exceeds biological necessities, i.e. there is an intrinsic and independent joy brought about by merely discovering the world. This joy is explained, in Schachtel's view, by the satisfaction the child experiences when she is connected to others and the world. Further, since Schachtel doesn't think of the dynamic of individuation as traumatic, the kind of uniting effort such as that sought out through Freud's 'oceanic' feeling can be positive and desirable. ${ }^{31}$ This is the case so long as the transition from the symbiotic moment to the moment of individuation is dynamic. For this dynamism to be possible at all the child must have a secure sense of self, which Schachtel describes as one that can tolerate both difference and continuity between self and world. This in turn enables an attention for the world and its objects that is not only vested with or contingent upon one's needs and desires. ${ }^{32}$ Schachtel calls this attention allocentric perception. He calls the instrumentalizing perception which opposes allocentric perception 'autocentric perception'.

Keller uses Schachtel's developments on perception to discuss what I alluded to earlier: a particular conception of autonomy and its relationship with objectivity. Keller terms the traditional conception of autonomy, i.e. one in which one sees oneself as separated from and impermeable to the world, static autonomy. Keller adds, however, that the allocentric perception that I just mentioned allows for another conception of autonomy, which she calls dynamic autonomy. This autonomy requires that one trust her capacities and abandon the delusion that she is fully self-sufficient, can act independently of the world and others, or can avoid being acted upon. This will allow 'for that vital element of ambiguity at the interface between subject and object. $^{\text {,3 }}$

The notions of objectivity corresponding to dynamic and static autonomy are dynamic and static objectivity. 'Dynamic objectivity aims at a form of knowledge that grants to the world around us its independent integrity but does so in a way that remains cognizant

31 Ernst Schachtel, Metamorphosis: On the Conflict of Human Development and the Psychology of Creativity (New York: Routledge, 2001), p. 182.

32 Keller, Reflections on Gender and Science, p. 119.

33 Ibid., p. 84, my emphasis. 
of, indeed relies on, our connectivity with that world: ${ }^{34}$ Keller compares this sort of objectivity to empathy. Like empathy, then, dynamic objectivity is an objectivity that mobilizes shared experiences and emotions between the subject and object of knowledge. ${ }^{35}$ In static objectivity, on the contrary, the understanding of the other can only be attained by separating and fracturing the subject from her object of knowledge, which involves dissociating the object from the subject so that the latter can instrumentalize it. This leads to a type of knowledge where difference is thought of in terms of frontiers and sharp edges. In this paradigm of objectivity, perception becomes an 'act of aggressive violence in which the perceiver, like Procrustes with his hapless victims, cuts off those aspects of the object which he cannot use for his purposes. $^{36}$

In sum, Keller's vision of the subject is not, strictly speaking, a 'decentring' of the subject in the sense that it makes the subject disappear. In fact, as we have just seen, Keller spends a significant amount of energy describing how a subject is formed, or individuated, and how that impacts her relationship to the world and therefore also to knowledge. My point is, however, that this dynamism of individuation - which at one point accepts a certain degree of separation and at another unites subject and object - forces us to think of the frontiers between subject and object as at least momentarily absent. This 'decentring of the subject' is the key, in my opinion, to answering the criticisms addressed to New Materialism which I have mentioned above.

\section{Longino's Critique of the Psychodynamism of Individuation}

Before addressing how the psychodynamism of individuation can help to answer the criticism addressed to New Materialism, let us turn to Longino's own criticism of the psychodynamism of individuation. Longino's characterization of the psychodynamism of individuation focuses on the aspect of the theory that attempts to show that 'cog-

\footnotetext{
$34 \quad$ Ibid., p. 117.

35 Ibid., p. 116.

36 Schachtel, Metamorphosis, p. 171, quoted by Keller, Reflections on Gender and Science, p. 120.
} 
nitive efforts have an ineluctably affective dimension. ${ }^{37}$ From that reading, therefore, she places Keller's psychodynamism of individuation alongside standpoint theory ${ }^{38}$ for both theories, in her opinion, aim to highlight the subjective conditionality of descriptive claims by emphasizing their 'social and historical location'. Her criticism of both theories is, therefore, that they 'fail to explain how we are to decide or to justify decisions between what seem to be conflicting claims. ${ }^{39}$ In other words, if subject $\mathrm{X}$ describes 'Phenomenon $\mathrm{A}$ ' as ' $\mathrm{a}$ ' and subject $Y$ describes 'Phenomenon $A$ ' as ' $b$ ', how are we to determine who is right?

Though Longino writes that both theories fail at answering this question, she also proposes that standpoint theory attempts to solve it by ascribing more epistemic authority to one subject based on their social and historical location. It is less clear how she thinks the psychodynamism of individuation ascribes epistemic authority, but she nevertheless criticizes it on the same grounds. For Longino, the 'analytical task is not to determine which is epistemically most adequate. Rather, the task is to understand how these complexly conditioned subjectivities are expressed in action and belief. ${ }^{40}$

This criticism resembles what we have seen earlier about the 'threat of anti-realism' directed at New Materialism. That is to say, that standpoint theory, the psychodynamism of individuation, and New Materialism all, to use Longino's wording again, 'fail to explain how we are to decide or to justify decisions between what seem to be conflicting claims.' It is indeed conceivable that the accounts of a phenomenon given by New Materialism would lead to different descriptive claims about that phenomenon. These accounts may change according to the apparatus involved. So how can Keller's psychodynamism of individuation help at all with the 'anti-realist' problems New Materialism seems to reiterate?

37 Longino, 'Subjects, Power and Knowledge', p. 108.

38 As a reminder, 'standpoint theory' argues that the subject of knowledge's position (be it their gender, 'race', socio-economic background, sexual orientation, mental and physical ability, etc.) has an influence on the type and quality of knowledge produced. Longino, 'Subjects, Power and Knowledge', p. 109.

40 Ibid. 


\section{Relational Ontology}

My hope is to have shown above that the psychodynamism of individuation, contrary to what Longino suggests, is not about lending epistemic superiority to one subject, but instead about redefining the epistemic subject altogether by redefining what could be called his or her epistemic virtues - a topic I will discuss in a moment - and by extending who/what counts as subject. This expansion of the subject is something this theory shares with New Materialism and what I have called here relational ontology. As for the redefinition of the subject's epistemic virtues, New Materialism already hints at the connection between ontology, epistemology, and ethics, but does not really expand upon the topic of epistemic virtues.

I have already claimed that New Materialism and the psychodynamism of individuation share a common shift in ontological terms. Indeed, what New Materialism and, I argue, Keller, ask us to do is to try to think of object and subject in terms of the relationship they have with one another, and how these relationships are shaped by and shape these entities, critters, or relata. In Keller, this shift in ontology is captured by her discussion of the 'vital element of ambiguity' ${ }^{41}$ and of the continuity between the subject and object, which questions the impermeability of both and highlights their inter/intra-dependence. Whereas in Haraway and Barad, the subject is 'heterogenous', 'nonisomorphic', and 'partial', 2 these descriptors all point to an ontology in which subject-object formation is not only co-constitutive, but in which the relation and cosmological organization bears more weight than its 'individual' components. Therefore, the subject is redefined as an emerging pattern of difference, which 'highlight [s], exhibit [s], and make[s] evident the entangled structure of the changing and contingent ontology of the world, including the ontology of knowing. ${ }^{43}$

Furthermore, both, beyond offering a different ontology, propose in and by this ontology, an ethical framework. The suggestion that the self cannot be defined or thought of outside of its relationships has two major ethical consequences. First, it allows for a much more dynamic

41 Keller, Reflections on Gender and Science, p. 84.

42 Haraway, 'Situated Knowledges', p. 586.

43 Barad, Meeting the Universe Halfway, p. 73. 
(and emancipating?) self-understanding. That is, one that is not confined to only one or to a cumulative list of identity. This 'departure from identity' is not, however, reducible to a non-identity, or a point of view from nowhere, i.e. a detached conception of objectivity which aims to paradoxically embody the universal. The positionality of every element in the pattern of diffraction is and has to be taken into account! But that account, or census of positions, does not determine future outcomes, nor does it sanction the attribution of blame. The causal chain of the elements taken into account is neither linear nor monocausal, and it is therefore neither reproducible nor predictable. Thus, identity is both constrained by some parameters and, at the same time, understood as contingent: it is processual.

\section{Processualism and Allocentric Perception}

I would now like to discuss processuality and return to the question of how a reading of the psychodynamism of individuation may answer some criticism addressed to New Materialism. Processuality is precisely what helps reveal how the 'complexly conditioned subjectivities' Longino worries about 'are expressed in action and belief'. Keller's understanding of processuality involves 'the growing interest among physicists in a process description of reality', whereby 'object reality acquires a dynamic character, akin to the more fluid concept of autonomy emerging from psychoanalysis. ${ }^{44}$ Indeed, where the psychodynamism of individuation can benefit New Materialism, I argue, is precisely through these processual, dynamic descriptions of the world that a 'more fluid concept of autonomy' allows for.

Therefore, and as a first response to this anxiety about the spectre of anti-realism, the psychodynamism of individuation helps us to understand how the agential cuts into phenomena are made at the human level. That is to say, according to which interests, motivations, and to what end those cuts are made. It emphasizes that knowledge claims are not innocent and devoid of emotional or libidinous investments (in the terms of New Materialism, these emotional-libidinous investments may be considered part of the apparatus). It does not contend, how-

44 Keller, Reflections on Gender and Science, p. 94. 
ever, that these emotional investments are any ground to reject one claim in favour of another (allegedly less invested) or to hierarchize them into better or lesser claims. Instead, the psychodynamism of individuation calls for an investigation into these emotional-libidinous investments - as real material objects - so that we can share fuller accounts of phenomena.

Second, and while recognizing that this objective may not be achievable (immediately or forever), the psychodynamism of individuation provides us with an insight into the problem of a shared account of the world. Indeed, with allocentric perception and dynamic objectivity, a sketch of what Mirenda Fricker has called epistemic virtues emerges. ${ }^{45}$ Though Fricker's theory of epistemic virtues is of inestimable help in the realm of judiciary testimonies as a transitional or intermediate tool in this specific context, my point of departure or premise is that, ultimately, for most knowledge projects, the sort of unbiased judgement she is after is impossible, and may not even be desirable. Therefore, in this quest for epistemic virtues, the orientation would be towards those that result in the questioning of one's own authority and the room that is opened up as a consequence for different and possibly conflicting accounts. These virtues, in common language, might be called generosity, benevolence, patience, and curiosity though I am hesitant to propose anything that is definitive here, and by giving these examples I only wish to make my meaning as clear as possible. What I can say about these virtues at this point, however, is that in practice they would be of the sort that maximize the possibility for a common ground - even when the language we use seems to lead to deadlocks and contradictions regarding any phenomenon's description.

The examples I have given may seem to put the onus of the epistemological enterprise on the 'listener' rather than the 'speaker' of some information. I want to suggest, however, that the onus is in fact shared between the parties. This is because one finds oneself in either position at different times and also because these virtues, if we come back to the examples of generosity, benevolence, patience, and curi-

45 Miranda Fricker, 'The Virtue of Testimonial Justice', in Epistemic Injustice: Power and the Ethics of Knowing (Oxford: Oxford University Press, 2007), pp. 86-108. 
osity, do not make a demand upon the 'listener' alone. Indeed, in the way she conveys information a speaker can prove to be more or less generous, benevolent, patient, and curious towards her interlocutor. Keller alludes to this when she points to the empathy that dynamic objectivity requires and which consists in finding a common language in shared experiences and emotions. ${ }^{46}$ The psychodynamism of individuation therefore suggests that if non-instrumentalized perception is possible, there is finally no such thing as a fully disinvested perception. That is, this non-instrumentalized perception will have to find a common language in shared experiences and emotions which implies an emotional investment. If we accept that perception is always-already oriented and invested, what we need for finding a common ground is a way of accessing multiple grids of analysis. I contend that this is precisely what allocentric perception and dynamic objectivity offer.

Third, this encounter between New Materialism and the psychodynamism of individuation has the advantage of addressing the threat of idealism (understood as anti-realism) by encouraging doubt about the ego's separation from the world and also encouraging processual reflexivity, which forces us to face the ways in which the ego affects objects and how objects, in turn, affect the subject. Indeed, when the subject enters this ambiguous space in which the object affects her completely, there is as little doubt about the object's presence as there is about her own. Keller's psychodynamism of individuation therefore gives us the means to face and negotiate the ambiguity between the inside and the outside without negating our sense of self.

Fourth, and regarding the question of accountability in the face of a dislocated subject, I contend that agenthood, and hence accountability, in this ontological paradigm is not a matter of tracing back intention and therefore responsibility to the original misbehaviour in order to 'punish the mistake' of a 'unified,' 'coherent', 'free-acting' subject. Rather, this accountability is one which encourages doubt about one's own presence as a coherent unit, ${ }^{47}$ and, by extension, encourages doubt about one's own (epistemological and ethical) omnipotence. This accountability is one which demands that the subject locate her-

46 Keller, Reflections on Gender and Science, p. 116.

47 Haraway, 'Situated Knowledges', pp. 585-86. 
self in the maelstrom of forces pushing her around and thus that she identify where her power lies. Further, this accountability is one that demands 'reponsibility for difference', for where one places the fateful line between self and everything else. ${ }^{48}$ This doubt results in what Haraway calls the 'possibility of webs of connections', which are 'called solidarity in politics and shared conversations in epistemology. ${ }^{\text {' }} 9$ This alliance between New Materialism and the psychodynamism of individuation hence shifts the focus from a cartography of matter that demands exhaustive models aimed at predicting future outcomes or at attributing blame to one that dynamically demands responses (personal and collective) to depleting circumstances. In sum, how we arrive where we are does matter (to get out of immobilizing blame and shame), but it matters less than how we can fix/change the depleting circumstances and move forward collectively, whether that be through reparations, mediation, or separation. 
Émilie Filion-Donato, 'Psychodynamism of Individuation and New Materialism: Possible Encounters', in Materialism and Politics, ed. by Bernardo Bianchi, Emilie Filion-Donato, Marlon Miguel, and Ayşe Yuva, Cultural Inquiry, 20 (Berlin: ICI Berlin Press, 2021), pp. 233-52 <https://doi.org/10.37050/ci-20_ $13>$

\section{REFERENCES}

Althusser, Louis, 'The Underground Current of the Materialism of the Encounter', in Philosophy of the Encounter: Later Writings, 1978-87, ed. by François Matheron and Oliver Corpet, trans. by Geoffrey M. Goshgarian (London: Verso, 2006), pp. 163-207

Aron, Raymond, Le Marxisme de Marx (Paris: Editions de Fallois, 2002)

Barad, Karen, Meeting the Universe Halfway: Quantum Physics and the Entanglement of Matter and Meaning (Durham, NC: Duke University Press, 2007) <https://doi.org/10.1215/ 9780822388128>

'Posthumanist Performativity: Toward an Understanding of How Matter Comes to Matter', Signs: Journal of Women in Culture and Society, 28.3 (2003), pp. 801-31 <https: //doi.org/10.1086/345321>

Bennett, Jane, 'Introducing the New Materialisms', in New Materialisms, ed. by Diana Coole and Samantha Frost (Duke University Press, 2010), pp. 1-43 <https://doi.org/10.1215/ 9780822391623>

— Vibrant Matter: A Political Ecology of Things (Durham, NC: Duke University Press, 2010) <https://doi.org/10.1215/9780822391623>

Bianchi, Bernardo, Emilie Filion-Donato, Marlon Miguel, and Ayşe Yuva, 'From 'Materialism' towards 'Materialities", in Materialism and Politics, ed. by Bernardo Bianchi, Emilie Filion-Donato, Marlon Miguel, and Ayşe Yuva, Cultural Inquiry, 20 (Berlin: ICI Berlin Press, 2021), pp. 1-18<https://doi.org/10.37050/ci-20_000>

Braidotti, Rosi, Metamorphoses: Towards a Materialist Theory of Becoming (Oxford: Blackwell, 2002)

Dolphijn, Rick, and Iris van der Tuin, New Materialism: Interviews \& Cartographies (Ann Arbor, MI: Open Humanities Press, 2012) <https://doi.org/10.3998/ohp.11515701. 0001.001>

Engels, Friedrich, Anti-Dühring, in MECW, xxv (1987), pp. 1-309

Fausto-Sterling, Anne, Sexing the Body: Gender Politics and the Construction of Sexuality, rev. edn (New York: Basic Books, 2000)

Fraser, Mariam, Sarah Kember, and Celia Lury, 'Inventive Life: Approaches to the New Vitalism, Theory, Culture \& Society, 22.1 (2005), pp. 1-14 <https://doi.org/10.1177/ 0263276405048431>

Freud, Sigmund, Civilization and its Discontents, in The Standard Edition of the Complete Psychological Works of Sigmund Freud, ed. by James Strachey, trans. by Angela Richards, 24 vols (London: Hogarth Press and the Institute of Psycho-Analysis, 1953-74), xxi (1961), pp. 57-145 
Fricker, Miranda, 'The Virtue of Testimonial Justice', in Epistemic Injustice: Power and the Ethics of Knowing (Oxford: Oxford University Press, 2007), pp. 86-108 <https://doi.org/10. 1093/acprof:oso/9780198237907.003.0005>

Grosz, Elizabeth A., The Nick of Time: Politics, Evolution, and the Untimely (Durham, NC: Duke University Press, 2004) <https://doi.org/10.1215/9780822386032>

— Volatile Bodies: Toward a Corporeal Feminism (Bloomington: Indiana University Press, 1994)

Hacking, Ian, The Social Construction of What? (Cambridge, MA: Harvard University Press, 1999)

Haraway, Donna J., 'The Promises of Monsters: A Regenerative Politics for Inappropriate/d Others', in Cultural Studies, ed. by Lawrence Grossberg, Cary Nelson, and Paula A. Treichler (New York: Routledge, 1992), pp. 295-337

— 'Situated Knowledges: The Science Question in Feminism and the Privilege of Partial Perspective', Feminist Studies, 14.3 (1988), pp. 575-99 <https://doi.org/10.2307/ 3178066>

Hill Collins, Patricia, 'Learning from the Outsider Within: The Sociological Significance of Black Feminist Thought', Social Problems, 33.6 (1986), pp. 14-32<https://doi.org/10. 1525/sp.1986.33.6.03a00020>

Itokazu, Ericka Marie, 'Temporality and History in Spinoza: The Refusal of Teleological Thought', in Materialism and Politics, ed. by Bernardo Bianchi, Emilie Filion-Donato, Marlon Miguel, and Ayşe Yuva, Cultural Inquiry, 20 (Berlin: ICI Berlin Press, 2020), pp. 55-72 <https://doi.org/10.37050/ci-20_03>

Keller, Evelyn Fox, Reflections on Gender and Science (New Haven, CT: Yale University Press, 1985)

Laqueur, Thomas, Making Sex: Body and Gender from the Greeks to Freud (Cambridge, MA: Harvard University Press, 2003)

Longino, Helen E., 'Subjects, Power, and Knowledge: Description and Prescription in Feminist Philosophies of Science', in Feminist Epistemologies, ed. and intro. by Linda Alcoff and Elizabeth Potter (New York: Routledge, 1993), pp. 101-20

Malm, Andreas, 'Against Hybridism: Why We Need to Distinguish between Nature and Society, Now More than Ever', Historical Materialism, 27.2 (2019), pp. 156-87 <https: //doi.org/10.1163/1569206X-00001610>

- The Progress of This Storm: Nature and Society in a Warming World (London: Verso, 2018)

Mathieu, Nicole-Claude, L'Anatomie politique: catégorisations et idéologies du sexe (Paris: Côtéfemmes, 1991)

Petersen, Eva Bendix, “Data Found Us”: A Critique of Some New Materialist Tropes in Educational Research', Research in Education, 101.1 (2018), pp. 5-16 <https://doi.org/ $10.1177 / 0034523718792161>$

Schachtel, Ernst, Metamorphosis: On the Conflict of Human Development and the Psychology of Creativity (New York: Routledge, 2001)

Spinoza, Benedictus de, The Collected Works of Spinoza, ed. and trans. by Edwin Curley, 2 vols (Princeton, NJ: Princeton University Press, 1985-2016)

Van Puymbroeck, Birgit, and N. Katherine Hayles, “Enwebbed Complexities”: The Posthumanities, Digital Media and New Feminist Materialism', DiGeSt: Journal of Diversity and Gender Studies, 2.1-2 (2015), pp. 21-29<https://doi.org/10.11116/jdivegendstud.2.1$2.0021>$

Visentin, Stefano, 'Non Defuit Materia: Freedom and Necessity in Spinoza's Democratic Theory', in Materialism and Politics, ed. by Bernardo Bianchi, Emilie Filion-Donato, Marlon Miguel, and Ayşe Yuva, Cultural Inquiry, 20 (Berlin: ICI Berlin Press, 2020), pp. 39-54 <https://doi.org/10.37050/ci-20_02> 
Žižek, Slavoj, Absolute Recoil: Towards a New Foundation of Dialectical Materialism (London: Verso: 2014) 